Retraction

\title{
Retracted: Antenatal Steroid Therapy for Fetal Lung Maturation and the Subsequent Risk of Childhood Asthma: A Longitudinal Analysis
}

\author{
Journal of Pregnancy \\ Received 6 September 2016; Accepted 6 September 2016 \\ Copyright (C) 2016 Journal of Pregnancy. This is an open access article distributed under the Creative Commons Attribution License, \\ which permits unrestricted use, distribution, and reproduction in any medium, provided the original work is properly cited.
}

Journal of Pregnancy has retracted the article titled "Antenatal Steroid Therapy for Fetal Lung Maturation and the Subsequent Risk of Childhood Asthma: A Longitudinal Analysis" [1]. The article was found to contain a substantial amount of material from the following published article by the same authors: D. Pole, C. A. Mustard, T. To, J. Beyene, and A. C. Allen, "Antenatal steroid therapy for fetal lung maturation: is there an association with childhood asthma?" Journal of Asthma, vol. 46, no. 1, pp. 47-52, 2009. That article was cited in the "Methods" section, but not discussed.

\section{References}

[1] J. D. Pole, C. A. Mustard, T. To, J. Beyene, and A. C. Allen, "Antenatal steroid therapy for fetal lung maturation and the subsequent risk of childhood asthma: a longitudinal analysis," Journal of Pregnancy, vol. 2010, Article ID 789748, 9 pages, 2010. 